\title{
Medical History Collection Day
}

National Cancer Institute

\section{Source}

National Cancer Institute. Medical History Collection Day. NCI Thesaurus. Code C83329.

The day of the week a medical history data was collected. 